\title{
The Effect of Heating on the Surface Charge of Copper Oxide Nanorods
}

\author{
Shubhra Gangopadhyay*, Rajesh Shende*, Shameem Hasan*, and Louis M. Ross Jr.** \\ * Department of Electrical and Computer Engineering, University of Missouri, \\ Columbia, MO 65211 \\ ** Electron Microscopy Core, University of Missouri, Columbia, MO 65211
}

Surface charge, one of the important characteristics of energetics, depends mainly on various physical and chemical properties of the material. A charge may develop from defects in the materials such as vacancies, interstitials and electronic carriers in the bulk crystals. Under the influence of electrical fields, surface charge present on the ionic crystal develops a space charge layer [1]. However, if a charge imbalance exists between the surface charge on the material and the static electric field, the electrostatic energy will try to quickly override the charge neutrality in the total volume of bulk material. This static sensitive energetic material may cause accidental ignition. This study examines the surface charge on an oxidizer at different temperatures.

The oxidizer (copper oxide nanorods) was synthesized by a wet chemical process using the surfactant templating approach. To synthesize copper oxide nanorods, copper chloride and sodium hydroxide $(5: 3)$ were mixed thoroughly in presence of polyethylene glycol. The reaction is moderately exothermic, produces $\mathrm{Cu}(\mathrm{OH})_{2}$ through a series of olation and oxolation reaction, which on dehydration yields $\mathrm{CuO}$. The solid precipitated in the solution nucleates into nanorods due to the surface charge present on inorganic species. A transmission electron microscopy (TEM) image of $\mathrm{CuO}$ is shown in Figure 1. The length of the nanorods ranges from 70-90 $\mathrm{nm}$ and their width from 10-20 nm giving an aspect ratio of 5-7. The nanorods prepared by this method may contain impurities which can play a significant role in the surface charge equilibrium involving the positively and negatively charge in the copper oxide surface. Such impurities present in the surface can be removed by washing with ethanol and deionized water followed by high temperature annealing process. Morphological changes in the $\mathrm{CuO}$ heated to $600{ }^{\circ} \mathrm{C}$ can be seen in the scanning electron microscope (SEM) image in figure 2. Elemental "bulk" analysis was determined by energy dispersive spectroscopy (EDS) at different temperatures (See Figure 3). The SEM/EDS analysis, normalized to $100 \%$, shows the carbon content in the sample decreased from $19.4 \%$ to $4.0 \%$ with the increase of temperature from $100^{\circ} \mathrm{C}$ to $600^{\circ} \mathrm{C}(\mathrm{Table} 1)$. Potentiometric titration was performed to evaluate the surface charge present on a thermite mixture of copper oxide and aluminum particles, which was prepared by sonicating in 2-propanol. Copper nanorods were annealed at $400^{\circ} \mathrm{C}$ and $600^{\circ} \mathrm{C}$ and mixed with $\mathrm{Al}$ and subjected for surface charge analysis [2]. This mixture was deposited on silicon wafers by the spin coating technique. Figure 4 is a SEM image of the cross-section of this mixture on a silicon wafer. The surface charge of two irregular dielectric surfaces $(\mathrm{CuO}$ and $\mathrm{Al})$ was found to be reduced with the reduction of carbon based impurities in the copper oxide nanorods (See Figure 5). The presence of carbon in the oxidizer may contribute to the build up of charge in thermite material.

\section{References}

[1] Monica Backhaus-Ricoult, Phys. Chem. Chem. Phys., 5 (2003), 2174.

[2] Guibal, E., Milot, C., and Roussy, J., Sep. Sci. and Technol., 35 (7) (2000), 1021. 


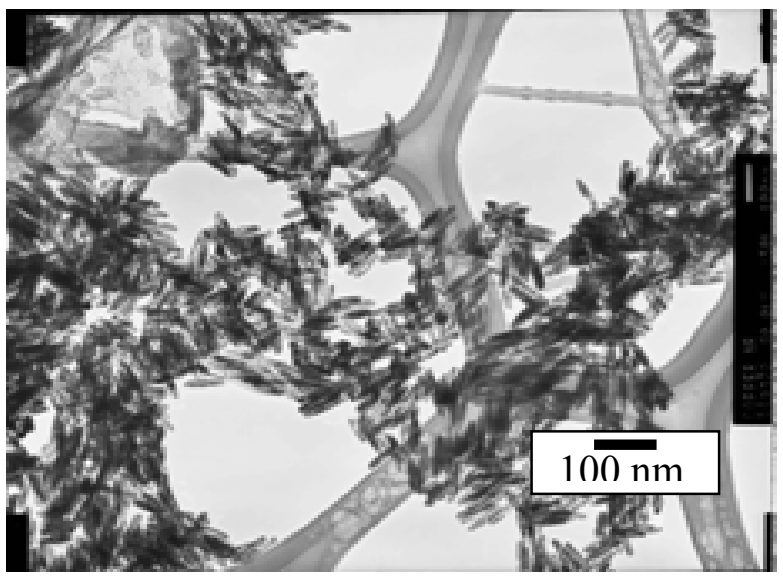

Fig. 1: TEM of $\mathrm{CuO}$ nanorods.

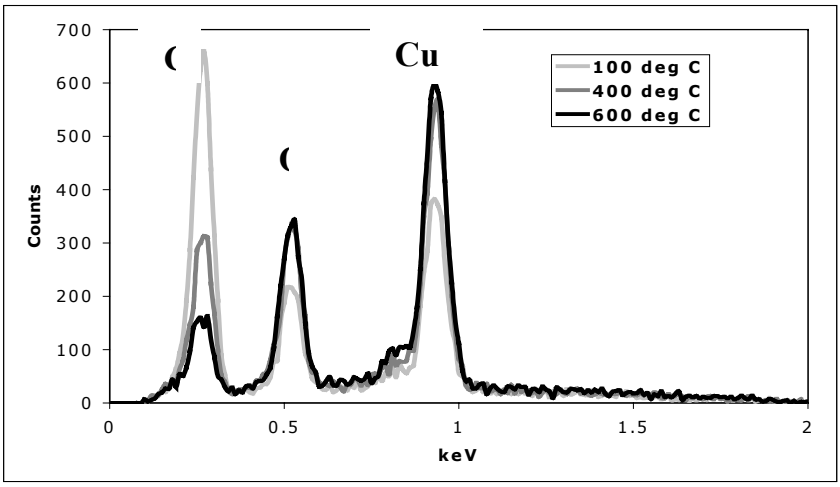

Fig. 3: EDS spectra of $\mathrm{CuO}$ samples at different temperatures.

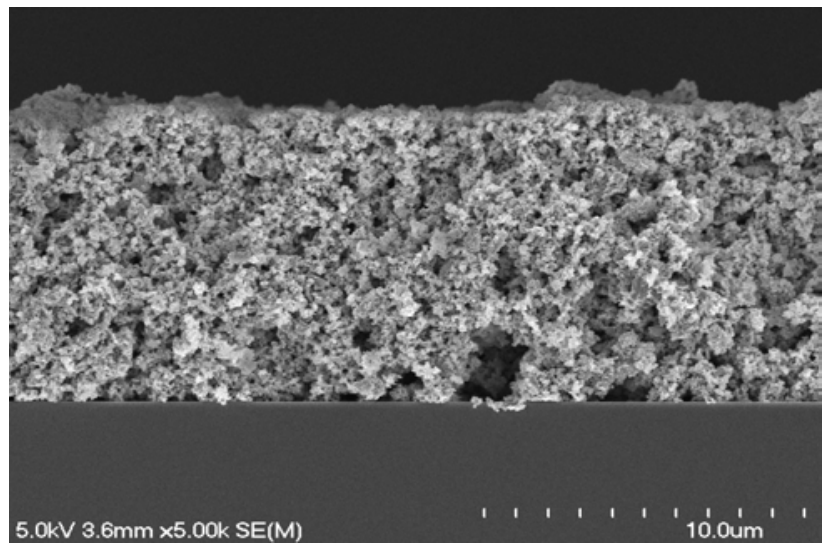

Fig. 4: SE image of $\mathrm{CuO}$ nanorods and aluminum nanoparticles on $\mathrm{Si}$ wafer.

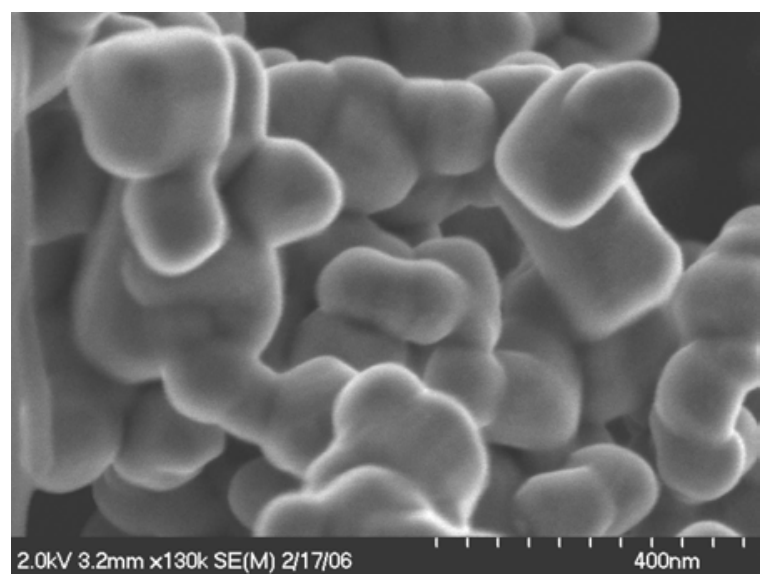

Fig. 2: SE image of $\mathrm{CuO}$ nanorods after heating to $600{ }^{\circ} \mathrm{C}$.

\begin{tabular}{|l|l|c|l|}
\hline Temp. & \multicolumn{3}{|c|}{ El. Wt. (\%) } \\
\hline${ }^{\circ} \mathrm{C}$ & $\mathrm{C} K$ & $\mathrm{O} K$ & $\mathrm{Cu} L$ \\
\hline 100 & 19.4 & 16.2 & 64.4 \\
\hline 400 & 7.8 & 18.5 & 73.7 \\
\hline 600 & 4.0 & 19.3 & 76.7 \\
\hline
\end{tabular}

Table 1: El. wt (\%) in the $\mathrm{CuO}$ nanorods samples at different temperatures.

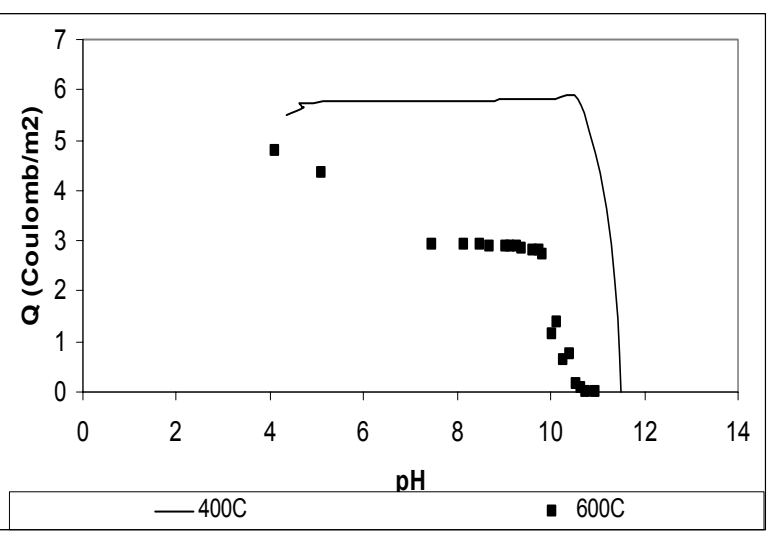

Fig. 5: Effect of carbon content on the surface charge of $\mathrm{CuO}$ and aluminum mixture. 